\section{AB1293-HPR DETERMINING FUNCTIONAL MOBILITY AND BALANCE FOR PATIENTS AFTER TOTAL KNEE ARTHROPLASTY: RELIABILITY OF L-TEST}

B. Unver ${ }^{1}$, E. Yuksel ${ }^{1}$, M. Eymir ${ }^{1}$, K. Sevik ${ }^{1}$, V. Karatosun ${ }^{2} .{ }^{1}$ Dokuz Eylul University, School of Physical Therapy and Rehabilitation, Izmir, Turkey; ${ }^{2}$ Dokuz Eylul University, Department of Orthopedics and Traumatology, School of Medicine, Izmir, Turkey

Background: Total knee arthroplasty (TKA) is a very common procedure, particularly implemented for the treatment of knee osteoarthritis (OA). Patient expectations after TKA surgery now include being able to enjoy appropriate recreational activities representing ambulatory activities beyond that of just pain relief and adequate knee motion (1). Since recreational activity comprises of more complex functions and requires longer standing durations, walking for 6-meter in a straight line in the timed up and go test (TUG) does not fully reflect the functional capacity of patients with TKA, and TUG test may be limited to detect the balance and mobility capacity in TKA patients $(2,3)$. As such, there is a need to determine more effective and functional evaluation tools that better reflect realistic situations in order to assess ambulatory performance level for patients with TKA. However, no studies have been conducted in patients with TKA to examine the applicability of the L-test, which assesses ambulation of individuals and consists of complex mobilization activity.

Objectives: The purposes of this study were to determine the test-retest reliability and the minimal detectable change (MDC) of the L-test for TKA patients.

Methods: Twenty-four patients with TKA due to knee OA, operated by the same surgeon, were included in this study. Patients performed trials for L-test twice on the same day. Between the first and second trials, patients waited for an hour on sitting position to prevent fatigue. The tester recorded the performance time while the participant was asked to get up from a chair, walk $3 \mathrm{~m}$ in a straight line, turn right, continue walking for $7 \mathrm{~m}$ in a straight line, turn left, walk back along the same path and sit down in the chair at their usual walking speed. Prior to the real testing session, the L-test was demonstrated by the tester and all participants were allowed to a practice trial.

Results: The L-test showed an excellent test-retest reliability $($ ICC2,1=0,98) in this study. Standard error of measurement (SEM) and MDC ${ }_{95}$ for L-test were 1,01 second and 2,8 second, respectively.

Conclusion: This study found that the L-test is a reliable test for patients following TKA. Overall, the excellent test-retest reliability of the L-test indicates that it may be an applicable standardized method to assess TKA patients who are able to walk greater distances and have better gait in more functional situations. Clinicians and researchers can be confident that changes in L-test time above 2,8 seconds, represent a "real" clinical change in an individual patient with TKA. We, therefore, recommend the use of L-test as complementary outcome measures for balance and functional evaluation in TKA patients.

References:

[1] Swinkels, A., \& Allain, T. J. (2013). Physical performance tests, self-reported outcomes, and accidental falls before and after total knee arthroplasty: an exploratory study. Physiotherapy theory and practice, 29(6), 432-442.

[2] Deathe, A. B., \& Miller, W. C. (2005). The L test of functional mobility: measurement properties of a modified version of the timed "up \& go" test designed for people with lower-limb amputations. Physical therapy, 85(7), 626-635.

[3] Kim, J. S., Chu, D. Y., \& Jeon, H. S. (2015). Reliability and validity of the L test in participants with chronic stroke. Physiotherapy, 101(2), 161-165.

Disclosure of Interests: None declared

DOI: 10.1136/annrheumdis-2020-eular.4789

\section{AB1294-HPR LOW CONCENTRATIONS OF BIOLOGIC DMARDS IN BREASTMILK OF PATIENTS TREATED DURING LACTATION}

A. Zbinden ${ }^{1}$, K. Eriksson ${ }^{1}$, F. Förger ${ }^{1}{ }^{1}$ University Hospital and University of Bern, Inselspital, Department of Rheumatology, Immunology and Allergology, Bern, Switzerland

Background: There is very limited information about the passage of biologics into breast milk and into the peripheral blood of breastfed infants. However, based on pharmacological properties of biologic DMARDs (bDMARDs) lactation may not be discouraged in patients with chronic inflammatory rheumatic disease to treat or prevent postpartum relapses. We here report two cases treated with bDMARDs during lactation: one woman with Muckle-Wells syndrome (MWS) treated with canakinumab and one woman with microscopic polyangiitis (MPA) treated with rituximab.
Objectives: To determine the level of rituximab and canakinumab in breast milk, in sera of breastfed infants as well as in sera of the mother and to calculate the average daily infant dose and the relative infant dose.

Methods: Serum and milk levels of Rituximab were measured by ELISA using commercially available coating and detection antibodies. For Canakinumab an ELISA was established by coating of plates with recombinant human IL-1beta and detection of Canakinumab in samples by a polyclonal anti-human IgG coupled to HRP. In both cases separate standard curves for serum and milk were established. Serum samples and milk samples of unexposed healthy controls were used to determine the lower limit of quantification.

Results: One patient with MWS received canakinumab $150 \mathrm{mg}$ s.c. to treat a worsening of her disease ten days postpartum. She continued to breastfeed her child. The average concentration of canakinumab in milk samples collected on 10 consecutive days was $15.8 \mathrm{ng} / \mathrm{ml}$. The average daily infant dose was $0.002 \mathrm{mg} /$ $\mathrm{kg} /$ day. The relative infant dose, which refers infant to maternal exposure on a dose/weight basis, was $0.11 \%$. There was no detectable canakinumab in the serum of the infant.

One patient with MPA received rituximab $500 \mathrm{mg}$ i.v. as a remission maintenance therapy four months postpartum. She continued to breastfeed her child. The average concentration of rituximab in milk samples collected on 4 consecutive days was $3.71 \mathrm{ng} / \mathrm{ml}$. The average daily infant dose was $0.001 \mathrm{mg} / \mathrm{kg} /$ day. The relative infant dose was $0.01 \%$. There was no detectable rituximab in the serum of the infant.

Conclusion: Only minimal concentrations of canakinumab and rituximab can be detected in breastmilk. For both bDMARDs, the relative infant dose was below $1 \%$ of the maternal dose, which is considered unlikely to be of clinical concern The lack of detectable levels of canakinumab and rituximab in the infants' sera supports the notion of low oral bioavailability of large monoclonal antibodies. Together, the results are similar to those seen in TNF inhibitors which are regarded to be compatible with breastfeeding, yet more data are needed $(1,2,3)$ References:

[1] Götestam Skorpen C, Hoeltzenbein M, Tincani A, Fischer-Betz R, Elefant E, Chambers C, da Silva J, Nelson-Piercy C, Cetin I, Costedoat-Chalumeau N, Dolhain R, Förger F, Khamashta M, Ruiz-Irastorza G, Zink A, Vencovsky J, Cutolo M, Caeyers N, Zumbühl C, Østensen M. The EULAR points to consider for use of antirheumatic drugs before pregnancy, and during pregnancy and lactation. Ann Rheum Dis. 2016 May:75(5):795-810. doi: 10.1136/ annrheumdis-2015-208840. Epub 2016 Feb 17.

[2] Clowse ME, Förger F, Hwang C, Thorp J, Dolhain RJ, van Tubergen A Shaughnessy L, Simpson J, Teil M, Toublanc N, Wang M, Hale TW. Minimal to no transfer of certolizumab pegol into breast milk: results from CRADLE, a prospective, postmarketing, multicentre, pharmacokinetic study. Ann Rheum Dis. 2017 Nov;76(11):1890-1896. doi: 10.1136/annrheumdis-2017-211384. Epub 2017 Aug 16.

[3] Matro R, Martin CF, Wolf D, Shah SA, Mahadevan U. Exposure Concentrations of Infants Breastfed by Women Receiving Biologic Therapies for Inflammatory Bowel Diseases and Effects of Breastfeeding on Infections and Development. Gastroenterology. 2018;155(3):696-704. doi:10.1053/j. gastro.2018.05.040

Disclosure of Interests: Astrid Zbinden: None declared, Klara Eriksson: None declared, Frauke Förger Grant/research support from: Unrestricted grant from UCB, Consultant of: UCB, GSK, Roche, Speakers bureau: UCB, GSK DOI: 10.1136/annrheumdis-2020-eular.4431

\section{HPR Epidemiology and public health (including prevention)}

\section{AB1295-HPR PREGNANCY RISK IN CHILDBEARING AGE WOMEN WITH RHEUMATIC DISEASES}

E. Barriga-Maldonado ${ }^{1}$, C. M. Skinner Taylor ${ }^{1}$, L. Pérez Barbosa ${ }^{1}$, J. D. Ángulo ${ }^{1}$, F. Vázquez ${ }^{1}$, G. Figueroa-Parra', R. Pineda-Sic ${ }^{1}$, J. C. Riegatorres ${ }^{1}$, D. Á. Galarza-Delgado ${ }^{1}{ }^{1}$ Hospital Universitario Dr. José Eleuterio González, Servicio de Reumatología, Monterrey, Mexico

Background: Rheumatic diseases (RD) are more frequent in women, affecting them during childbearing age. Medications used to treat can interfere with fertility or increase the risk of miscarriages and congenital abnormalities; Disease control and therapy should be discussed with patients before and during pregnancy, in order to minimize adverse outcome (1). Barriers to adequate communication 